\title{
Medication Complications in Extracorporeal Membrane Oxygenation.
}

\author{
Ami G. Shah \\ Thomas Jefferson University \\ Michelle Peahota \\ Thomas Jefferson University \\ Brandi Thoma \\ Thomas Jefferson University \\ Walter K. Kraft \\ Thomas Jefferson University
}

Follow this and additional works at: https://jdc.jefferson.edu/pharmacyfp

Part of the Medical Pharmacology Commons, and the Pharmacy and Pharmaceutical Sciences Commons

Let us know how access to this document benefits you

\section{Recommended Citation}

Shah, Ami G.; Peahota, Michelle; Thoma, Brandi; and Kraft, Walter K., "Medication Complications in Extracorporeal Membrane Oxygenation." (2017). College of Pharmacy Faculty Papers. Paper 31.

https://jdc.jefferson.edu/pharmacyfp/31

This Article is brought to you for free and open access by the Jefferson Digital Commons. The Jefferson Digital Commons is a service of Thomas Jefferson University's Center for Teaching and Learning (CTL). The Commons is a showcase for Jefferson books and journals, peer-reviewed scholarly publications, unique historical collections from the University archives, and teaching tools. The Jefferson Digital Commons allows researchers and interested readers anywhere in the world to learn about and keep up to date with Jefferson scholarship. This article has been accepted for inclusion in College of Pharmacy Faculty Papers by an authorized administrator of the Jefferson Digital Commons. For more information, please contact: JeffersonDigitalCommons@jefferson.edu. 


\section{Medication Complications in Extracorporeal Membrane Oxygenation}

Corresponding Author: Ami G. Shah, PharmD

\section{$\underline{\text { Address }}$}

111 S. $11^{\text {th }}$ St. Philadelphia, PA 19107

amishah1221@gmail.com

\section{Author Information:}

Ami Shah, PharmD*, Michelle Peahota, PharmD*, Brandi Thoma, PharmD*, Walter K. Kraft, MD^

*Department of Pharmacy, Thomas Jefferson University Hospital

${ }^{\wedge}$ Department of Pharmacology and Experimental Therapeutics, Thomas Jefferson University

\section{Keywords}

Pharmacology, pharmacokinetics, therapeutic drug monitoring

\section{$\underline{\text { Key Points }}$}

- $\mathrm{ECMO}$ is associated with physiologic and biomechanical changes that can impact drug disposition

- There is typically limited data describing changes in drug pharmacokinetic parameters for patients treated with ECMO.

- Changes in pharmacokinetics are often drug-specific

- Extrapolation of ECMO data from neonatal literature is limited due to significant differences in body composition and elimination pathways

- Therapeutic drug monitoring, when possible, should be considered to individualize therapeutics in patients receiving ECMO therapy

\section{Synopsis}

The need for ECMO therapy is a marker of disease severity, for which multiple medications are required. The therapy causes physiological changes which impact drug pharmacokinetics. These changes can lead to exposure driven decreases in efficacy or increased incidence of side effects. 
The pharmacokinetic changes are drug specific and largely undefined for most drugs. We review available drug dosing data and provide guidance for use in the ECMO patient population. 


\section{Introduction}

Critically ill patients have alterations in the pharmacokinetic (PK) parameters which describe drug absorption, distribution, metabolism, and excretion. These disturbances arise from the acute response of critical illness, including systemic inflammatory responses, organ dysfunction, altered tissue permeability, pH disturbances, changes in intra or extravascular space, fluid shifts, or decreased protein concentration. These pharmacokinetic alterations are relevant as they may precipitate unexpected medication toxicities or impair efficacy. In order to optimize patient outcomes, PK changes should be as best possible identified when developing medication regimens for critically ill patients. ${ }^{1-4}$

\section{ECMO and Pharmacokinetics}

Mechanical ventilation, renal replacement therapy, and extracorporeal membrane oxygenation (ECMO) $)^{5-8}$ can impact drug disposition and complicate the management of critically ill patients. During ECMO therapy, a large volume of blood is extracted from the venous system and is circulated outside the body into an oxygenator. A typical ECMO circuit consists of polyvinyl chloride (PVC) tubing, a hollow fiber (polymethylpentene) oxygenator, and a heat exchanger ${ }^{9}$ (Figure 1 ). PK changes during critical illness are often more pronounced in the presence of ECMO. Several aspects such as the sequestration of medications in the ECMO circuit, increased volume of distribution, and alterations in organ perfusion may alter PK parameters in ECMO patients..$^{5,7,9-12}$ (TABLE 1)

The effect of ECMO therapy on pharmacokinetics varies and is not fully elucidated for the majority of drugs. Investigating the impact of the ECMO circuit and its resulting physiologic changes on pharmacokinetics and pharmacodynamics is difficult given the limited patient population upon which to generate data. The ECMO population is numbered because ECMO is often a salvage therapy offered by limited number of centers. The available data investigating ECMO therapy is not only limited in size, but is typically also observational since it is difficult to conduct randomized trials with a control group. While there is some literature available in neonatal populations, it is difficult to generalize this data to adult populations. ECMO technology is frequently evolving, and circuits' manufacturers and materials vary, further limiting data generalizability. Demands of clinical care and blood volume during critical illness make sparse PK sampling with population modeling methods the only feasible method to investigate drug pharmacokinetic parameters in these patients. While this approach can identify some covariates associated with differential drug disposition, it is not possible to generate precise PK parameters under a variety of clinical scenarios.

\section{Drug Sequestration}


Drug sequestration to the circuit is a common consequence of ECMO therapy. The loss of medication in the circuit depends on factors including surface area or the potential interaction of medications to various plastic components of the ECMO system. ${ }^{5}$ The type of circuit may also be a variable predictor influencing the level of drug sequestration. ${ }^{9,13,14}$ The presence and material of ECMO oxygenators may further result in drug recovery differences. ${ }^{15,16}$ The use of blood versus crystalloid priming agents may increase drug losses with specific medications such as fosphenytoin, fentanyl, and heparin..$^{9,11,17}$ The overall effect of priming ECMO circuits with crystalloids, colloids, or blood products on drug sequestration is poorly characterized. While saline is a commonly utilized priming agent for ECMO circuits, there is currently no standard recommendation or guidance surrounding the most optimal priming approach. Molecular drug properties such as lipophilicity, molecular size, ionization, and protein-binding characteristically influence the likelihood of drug sequestration in the ECMO circuit. Typically, lipophilic and highly protein-bound medications are significantly sequestered in the circuit. 9,18 PK parameters of hydrophilic medications are also affected secondary to hemodilution and other ECMOrelated pathophysiologic changes. Previous studies investigating the overall impact of drug sequestration have reported up to $50 \%$ of morphine and $40 \%$ of lorazepam sequestration at 24 hours with additional medication losses in older circuits. ${ }^{17}$ Most importantly, the sequestration phenomenon is unpredictable. While medications may be sequestered, the circuit may also continue to release the sequestrated product over time. Overall, the sequestration of medications in the ECMO circuit increases the volume of distribution (Vd) which ultimately causes lower or suboptimal drug concentrations in the body (Figure 2)

\section{Volume of Distribution}

Volume of distribution $(\mathrm{Vd})$ is the hypothetical body space available for the medication to be diluted and distributed. Conceptually, $\mathrm{Vd}$ can be thought of as the relative fraction of drug that resides within the blood volume compared to that sequestered in extravascular compartments. Volume status and medication volume of distribution are highly relevant when predicting effective medication dosages for patients. Drug concentrations are measured in the central compartment and in variable fashion is a proxy for drug concentration at target, and thus drug effect. The therapeutic impact of an altered Vd is highest with medications with small volumes of distribution. For example, gentamicin is an aminoglycoside with a relatively small $\mathrm{Vd}$ of $0.2-0.3 \mathrm{~L} / \mathrm{kg}$ in healthy adults, or $18 \mathrm{~L}$ in an average $70 \mathrm{~kg}$ patient. A typical initial $2 \mathrm{mg} / \mathrm{kg}$ dose in this patient would lead to approximate therapeutic concentrations of $140 \mathrm{mg} / 18 \mathrm{~L}$, or $8 \mathrm{mg} / \mathrm{L}$. The target peak concentration of conventionally dosed gentamicin in severe gram negative infections is $8-10 \mathrm{mg} / \mathrm{L}$. Even slight changes in Vd may have a drastic impact on plasma concentrations. For example, the final concentration would be subtherapeutic at 
$5 \mathrm{mg} / \mathrm{L}$ if the $\mathrm{Vd}$ were increased to $0.4 \mathrm{~L} / \mathrm{kg}(28 \mathrm{~L})$ or supratherapeutic at $20 \mathrm{mg} / \mathrm{L}$ if the $\mathrm{Vd}$ were decreased to $0.1 \mathrm{~L} / \mathrm{kg}(\mathrm{LL})$. In contrast, medications with large volumes of distribution have the ability to diffuse from tissue reservoirs back into the circulating plasma. Unlike distribution to extravascular tissue, drug sequestered in tubing will not redistribute into the system when tubing is replaced. Other mechanisms by which ECMO has been found to increase $\mathrm{Vd}$ includes changes in plasma proteins from hemodilution or transfusions, organ dysfunction, $\mathrm{pH}$ alterations, and the activation of the systematic inflammatory response system. Most pharmacokinetic data in ECMO patients has originated from neonatal populations and in comparison to adults, neonates have a higher proportion of total body water, resulting in a higher Vd for hydrophilic medications. Additionally, neonates have decreased plasma protein binding, trapping less drug in the central compartment and resulting in a higher Vd for proteinbound medications. These differences between adult and neonatal populations limit the applicability of available ECMO PK data across the continuum of ages. . $^{5,11,19,20}$

Metabolism and excretion play significant roles in determining optimal medication dosages. A challenge often seen in ECMO patients involves changes in the rates of blood flow, which may alter tissue and organ perfusion. ${ }^{5}$ Kidney and liver hypoperfusion can impair medication metabolism and clearance leading to accumulation and potentially toxicity. Renal dysfunction (serum creatinine $>1.5 \mathrm{mg} / \mathrm{dL}$ ), a common occurrence during EMCO, has been reported to be as high as $32 \%$ in VV ECMO and $47 \%$ in VA ECMO. ${ }^{21}$ While VV ECMO utilizes pulsatile blood flow, VA ECMO incorporates higher flow rates with non-pulsatile blood flow. The mode disrupts typical blood flow since the kidneys interpret it as hypotension, causing a downstream activation of the renin-angiotensin system (RASS) ultimately leading to reduced urine production, an increased circulating volume, and thus an increased $\mathrm{Vd}$.,19 Much of the available PK data on ECMO have been reported in neonatal populations, who typically have immature enzymatic pathways and glomerular function. The impact of blood flow rates and hypoperfusion are yet to be described in the adult populations. Although the impact of renal hypoperfusion may be countered with the use of renal replacement therapy (RRT), the PK of ECMO patients on RRT is complex and variable. Therapeutic drug monitoring, whenever possible, is essential in this patient population. Additional research in this subset of patients is necessary to further guide treatment goals.

Sedation, analgesia, anticoagulation, treatment of infection, and diuresis are commonly encountered and are areas of concern in ECMO patients. Many medications from these classes have highly variable PK parameters which are unpredictable and patient dependent. While some medication classes such vasopressors and other cardioactive drugs can be titrated to patient response, others such as sedatives, have non-standardized endpoint measures. Others have no readily available biomarkers to 
follow, requiring in all cases the application of PK principles to achieve optimal therapeutic response..$^{22,23}$

\section{Sedatives/Analgesics-Opioids}

Sedatives and analgesics are utilized extensively in the ECMO population. Optimal sedation regimens are poorly defined due to inter-patient pharmacokinetic variability. The optimal sedative and analgesic agent depends on multiple PK considerations and patient-specific variables. ${ }^{24-26}$ In addition, there is a lack of a well-accepted pharmacodynamic (PD) endpoints to allow characterization of exposure/response relationships. Clinically, subjective agitation and ventilator dysynchrony are common measures of adequacy of sedation. Opioids are commonly used in the ICU as they provide both analgesia and sedation. The intravenous (IV) route of administration bypasses concerns for erratic absorption and also allows for faster onset and rapid titratability. ${ }^{27,28}$ While all full mu-agonist opioids can achieve equal levels of analgesia, each agent's potency and physiochemical characteristics serve as differentiating factors.

\section{Fentanyl}

Fentanyl, a lipophilic synthetic mu-opioid agonist with rapid onset and a short half-life, has been found to bind to the ECMO circuit extensively after 24 hours., 5 The level of fentanyl membrane absorption has been found to be variable dependent on the type of membrane oxygenator. ${ }^{13}$ Thus, fentanyl may be suitable for short-term analgesia however higher doses may be necessary to provide adequate sedation and analgesia, dependent on the type of membrane oxygenator beyond 24 hours. ${ }^{5,28}$ In contrast, the concentrations of morphine, a full mu-opioid agonist, are maintained despite ECMO therapy. Its minimal absorption to the ECMO circuit is likely due to morphine's hydrophilic nature. However, the clearance of morphine decreases up to $50 \%$ potentially due to hepatic hypoperfusion. ${ }^{5,29,30}$ The accumulation of morphine's active metabolite, especially in renal failure, may lead to prolonged sedation. Furthermore, morphine's histamine release may contribute to bronchospasm and hypotension. ${ }^{28}$ Clinicians should be aware of this dynamic accumulation, to allow down titration to clinical effect. ${ }^{17,29}$

\section{Hydromorphone}

Hydromorphone, a semisynthetic opiate, is an additional option for analgesia and sedation. Although there are no studies investigating its PK in ECMO, hydromorphone is expected to have minimal sequestration within the EMCO circuit due to its hydrophilicity. Unlike morphine, this agent does not have active metabolites and does not cause a histamine release when administered. Although meperidine is a full mu-opioid agonist, it should be avoided due to its potential for drug interactions 
with serotonergic and dopaminergic agents and metabolite accumulation leading to decreased seizure thresholds. ${ }^{28}$

\section{$\underline{\text { Ketamine }}$}

Adjunctive analgesic medications such as ketamine, an $\mathrm{N}$-methyl-D-aspartate antagonist, are demonstrated to augment opioid analgesia without influencing sympathetic tone. ${ }^{28,31}$ In addition to improved wakefulness due to decreased opioid utilization, low-dose ketamine infusions may also offer the advantage of producing amnestic effects. Ketamine has previously demonstrated the ability to decrease opioid or concurrent sedative requirements without altering RASS scores at doses ranging from $50-100 \mathrm{mg} / \mathrm{hr}$. These high doses may be a result of drug sequestration due to ketamine's lipophilic

nature. ${ }^{32}$ However, a randomized controlled trial of 20 ECMO patients showed no reduction in opioid or sedative requirements in patients with a low-dose ketamine infusion compared to a control group. ${ }^{33}$ Given the paucity and conflicting nature of available data and dosing practices, the optimal use of ketamine in ECMO patients has not yet been defined.

\section{Benzodiazepines}

While opioids alone may provide sufficient analgesia and sedation, some patients may require additional sedation to provide adequate comfort. Benzodiazepines activate gamma-aminobutyric acid receptors leading to anxiolysis, amnesia, and sedation. Midazolam, a benzodiazepine, is frequently utilized as an infusion given its rapid onset of action, relatively short half-life (2-5 hours), and intermediate duration. Despite being water soluble, midazolam is also highly lipophilic and has been shown to have significant sequestration in the ECMO circuit. Literature suggests that greater than $50 \%$ of midazolam may be sequestered with a majority in the first few hours of ECMO initiation. Significantly higher doses of midazolam are necessary with the introduction of ECMO due to this sequestration as well as the increased $\mathrm{Vd} .^{34}$ While higher doses may be necessary, accumulation of its active metabolite or liver and renal failure prolong the effect of midazolam, leading to excessive sedation and respiratory depression. ${ }^{28}$ This also may contribute to longer recovery times. Lorazepam is less lipophilic than midazolam leading to a lesser degree of ECMO circuit sequestration. ${ }^{17}$ Compared to midazolam, lorazepam has a longer half-life of 10-20 hours and does not have any active metabolites. However, caution is warranted, especially in using high doses and for prolonged periods due to the polyethylene glycol excipient that can cause potential renal toxicity.

\section{Propofol and Dexmedetomidine}

Non-benzodiazepine sedatives may also be used in conjunction with opioids to provide 
additional sedation. Propofol, a lipophilic and highly protein-bound agent, has been found to have significant sequestration within the ECMO circuit. ${ }^{35}$ This makes, propofol possibility a less desirable agent for sedative therapy for ECMO patients. ${ }^{28}$ Dexmedetomidine, an alpha 2-adrenergic agonist, has analgesic, anxiolytic and sedative properties. Patients sedated with dexmedetomidine are easily aroused. Compared to benzodiazepines, dexmedetomidine is associated with a reduced incidence of delirium, respiratory depression, and impact on sympathetic tone. ${ }^{27,36}$ If the patient requires deep sedation due to neuromuscular blockade, dexmedetomidine is not appropriate in monotherapy. Dexmedetomidine sequestration appear to occur early in the circuit and continue to decline throughout ECMO treatment. Despite these losses, the clearance of dexmedetomidine between old and new circuits has not been found to be statistically significant. Thus, dexmedetomidine may experience medication losses in ECMO circuits, either through sequestration or clearance. Dexmedetomidine therapy in ECMO patients requires monitoring and appropriate dose adjustments to ensure adequate serum concentrations. ${ }^{37}$

The approach to analgesia and sedation for ECMO patients should be patient specific. Choice of drug depends on level of sedation required due to the presence of neuromuscular blocking agents or instrumentation, patient characteristics such as previous drug exposure or tolerance, expected duration of therapy, and allergies. Institutional formulary restrictions, drug cost, shortages and local guidelines also help to guide therapy.

\section{Neuromuscular blockade:}

Neuromuscular blocking agents (NMBAs) may be utilized in ECMO patients in conjunction with sedatives to provide pharmacological skeletal muscle paralysis. These agents should be reserved for select situations in which paralysis is necessary to improve patient-ventilator synchrony, enhance alveoli recruitment and oxygenation, and reduce overall oxygen demand. ${ }^{38,39}$ Clinical practice patterns of pharmacological paralysis in ECMO patients is variable. ${ }^{24,25}$ Currently, there are no pharmacokinetic data available to tailor NMBA dosing for ECMO patients. Standard dosing and appropriate titration are recommended. Peripheral nerve stimulation testing such as train of four (TOF) monitoring is vital for paralytic assessment and NMBA titration. ${ }^{40}$ Patients receiving neuromuscular blockade must be also monitored for symptoms of ICU-acquired weakness, myopathy, and polyneuropathy. ${ }^{41}$

\section{Anticoagulation:}

As blood is exposed to non-biological surfaces and high shear stress, platelet activation and the coagulation cascade is triggered, putting patients at risk for clotting during ECMO. ${ }^{42-44}$ Additional factors 
provoking hypercoagulability during ECMO therapy include cannulation induced endothelial injury and blood flow disturbances. ${ }^{45}$ Even in settings of a variety of different pumps, membrane oxygenators, heat exchangers, and priming volumes, the overall impact on hemostasis is largely consistent. ${ }^{42,46}$ Methods such as coating non-endothelial surfaces with anticoagulants and systemic anticoagulation have been investigated to minimize the risk of thrombosis. Unfractionated heparin (UFH) is a standard and widely used anticoagulant. There is no standard dose of heparin currently recommended. Although sites may have institution-specific protocols for infusing UFH during ECMO, one method is to administer a heparin bolus of 70 units/kg at the time of vascular cannula insertion followed by a continuous infusion initiated at $18 \mathrm{units} / \mathrm{kg} / \mathrm{h}$ titrated to a goal activated partial thromboplastin time (aPTT) of 50-60 seconds. ${ }^{42}$ Therapeutic targets vary according to institution. An international survey investigating current practices of anticoagulation in ECMO patients has found that activated clotting time (ACT), antithrombin III, anti-factor Xa, and thromboelastography may be alternatives for anticoagulation monitoring. ${ }^{47}$ None of these are readily available at most institutions and their use has not been established to achieve better clinical outcomes than the use of PTT monitoring. Optimal targets for anticoagulation in ECMO patients remain unclear due to the delicate balance between thrombotic and hemorrhagic complications. ${ }^{48}$ Large systematic reviews have noted the rate of thrombosis in VV ECMO patients to be $53 \%$. Conversely, rates of gastrointestinal or intracranial hemorrhage in VV ECMO patients have been reported to be about $16 \%{ }^{42,48}$ Thrombotic and hemorrhagic rates have not yet been quantified in VA ECMO patients. In attempts to minimize bleeding complications, there have been reports of patients with heparin-coated ECMO circuits who have successfully omitted additional systemic anticoagulation without increasing thrombotic risk. ${ }^{49,50}$ Furthermore, heparin-free ECMO may be a consideration in select ECMO patients with severe trauma or extensive bleeding risks. ${ }^{51,52}$ The use of UFH as well as specific titration endpoints should be tailored to each patient's individualized thrombotic and hemorrhagic risk factors.

Although heparin is a suitable anticoagulant for most patients, $10-15 \%$ of ECMO patients have reported heparin-induced thrombocytopenia (HIT) syndrome. ${ }^{39}$ Heparin needs to be discontinued in this group of patients. ${ }^{53}$ Direct thrombin inhibitors, such as argatroban and bivalirudin are alternative agents for ECMO patients with HIT. ${ }^{39,54-58}$ The necessity of an initial argatroban bolus is controversial. Argatroban may be bolused with a range of $10-30 \mathrm{mcg}$. Case reports have documented ECMO patients to initiate standard doses of argatroban at $2 \mathrm{mcg} / \mathrm{kg} / \mathrm{min}$ and subsequently titrate to aPTT levels 1.5-3 times baseline without significant bleeding concerns. ${ }^{23}$ However, other reports note that typical argatroban infusion rates of $2 \mathrm{mcg} / \mathrm{kg} / \mathrm{min}$ have been associated with excessive anticoagulation and severe bleeding in ECMO patients. Comparatively, 10 -fold lower dosages of $0.2 \mathrm{mcg} / \mathrm{kg} / \mathrm{min}$ have been 
demonstrated to achieve appropriate levels of anticoagulation, defined as an aPTT range of 50-60 seconds. ${ }^{59,60}$ An additional case report notes that a starting dose of argatroban between 0.1 and 0.2 $\mathrm{mcg} / \mathrm{kg} /$ minute resulted in adequate anticoagulation without any thrombotic or hemorrhagic complications in a high bleeding risk patient as defined by a dosing weight $>90 \mathrm{~kg}$, bihrubin $>51.3$ $\mathrm{mmol} / \mathrm{L}$, and platelet count $<70 \times 10^{9} / \mathrm{L} .{ }^{61}$ Due to the lack of a consensus dosing method, it may be recommended to initiate argatroban at lower doses, especially in patients at high risk of bleeding. NonECMO critically ill patients also often have a variable dose response to argatroban, leading some clinicians to use regimens of 1 or $0.5 \mathrm{mcg} / \mathrm{kg} / \mathrm{min}$ as initial therapy. Bivalirudin is not preferred for all patients due to its high cost and lack of an antidote. Previous studies have utilized bivalirudin with or without a bolus loading dose followed by an infusion ranging from $0.1-0.2 \mathrm{mg} / \mathrm{kg} / \mathrm{h}$ to $0.5 \mathrm{mg} / \mathrm{kg} / \mathrm{h}$. Similar to heparin, there is no consensus for bivalirudin monitoring parameters. Reported monitoring strategies during bivalirudin therapy have ranged from aPTT 45-60 seconds to 42-88 seconds, ACT 180200 seconds to 200-220 seconds, and thromboelastography. ${ }^{62}$

The use of additional antithrombotic agents to minimize platelet activation and deposition in ECMO patients should be evaluated on a case to case basis. ${ }^{63}$ Aspirin, an irreversible cyclooxygenase (COX) inhibitor, is often recommended for the prevention of primary or secondary cardiovascular events. In ECMO patients, aspirin may also be beneficial to reduce platelet binding to the circuit. ${ }^{64}$ Adjunctive aspirin use in a single prospective cohort study with ECMO patients was not found to increase bleeding or transfusion requirements. ${ }^{65}$ Indication for aspirin should be individualized in patients with coagulation disorders or moderate to severe traumatic brain injury. Clopidogrel, an irreversible inhibitor of the $\mathrm{P} 2 \mathrm{Y}_{12}$ component of ADP receptors on platelets, has been evaluated in a small subset of patients with acute coronary syndrome receiving ECMO therapy. Although clopidogrel therapy may be associated with increased transfusion requirements, it has not been associated with a significant bleeding risk. ${ }^{66,67}$ Generally, dual antiplatelet therapy in patients with recent coronary stent implantation should not be withheld. ${ }^{64,68,69}$ Glycoprotein Ilb/Illa inhibitors may also be utilized in VA ECMO patients with recent percutaneous coronary interventions $(\mathrm{PCI})$. One retrospective observational study found that ECMO patients on glycoprotein Ilb/IIla inhibitors required an increased number of transfusions. ${ }^{66}$ The benefit and risk of additional antithrombotic agents should be evaluated on a case to case basis.

\section{$\underline{\text { Antibiotics }}$}

Antimicrobial regimens that optimize drug exposure relative to therapeutic concentrations maximize antimicrobial efficacy and decrease toxicity. More than other drug classes, antibiotic 
concentration is an effective biomarker linked to therapeutic success when extrapolating drug dosing between populations. This is the case in ECMO, in which there is a lack of comparative efficacy data to guide therapeutics. Although several antibiotics have been analyzed, few trials have been conducted in the adult ECMO population. Among the available studies in adult ECMO patients, results have demonstrated significant inter-patient variability. ${ }^{14,19,70,71}$

\section{Vancomycin}

Vancomycin, a glycopeptide antimicrobial, is a widely used broad-spectrum agent with activity against Staphylococcus, Streptococcus, and Enterococcus species. Vancomycin pharmacokinetics may be estimated by a ratio of the area under the concentration-time curve (AUC) to the minimum inhibitory concentration (MIC). ${ }^{72}$ A consensus review from the American Society of Health-System Pharmacists, the Infectious Diseases Society of America, and the Society of Infectious Diseases Pharmacists has established a vancomycin PK/PD parameter of an AUC/MIC ratio greater than 400 for serious infections. It is estimated that targeting vancomycin trough levels of $15-20 \mathrm{mg} / \mathrm{L}$ should achieve this AUC for organisms with relatively low MICs (MIC $\leq 1 \mathrm{mg} / \mathrm{L}$ ). Suggested vancomycin dosing to achieve these trough levels and ultimately AUC/MIC ratios includes a loading dose of $25-30 \mathrm{mg} / \mathrm{kg}$ based on actual body weight followed by a maintenance dose of $15-20 \mathrm{mg} / \mathrm{kg}$ every $8-12$ hours in patients with normal renal function. Individual pharmacokinetic adjustments should be made based on therapeutic drug monitoring. ${ }^{73}$ Though the PK parameters of vancomycin have been heavily studied, most trials in ECMO patients have only investigated pediatric and neonatal populations. Recent studies with mixed populations including neonates, children, and adults suggest an increased $\mathrm{Vd}$ and decreased clearance of vancomycin during ECMO therapy. ${ }^{20}$ Despite these changes in PK parameters, adult population models derived from smaller trials have found that no special dosing adjustments are required in ECMO patients. Pharmacometric modeling has demonstrated that standard dosing regimens may be adequate in achieving therapeutic trough concentrations, especially in obese patients on ECMO therapy. ${ }^{74}$ Nevertheless, standard vancomycin dosing regimens vary per institution. Some centers have investigated $35 \mathrm{mg} / \mathrm{kg}$ loading dose over 4 hours followed by a daily infusion adapted to creatinine clearance and renal function while others have used an initial 1 gram intravenous dose followed by 1 gram every 12 hours. ${ }^{75,76}$ The presence of renal dysfunction and interventions such as continuous renal replacement therapy or hemodialysis further complicate vancomycin dosing. Given the mixed data, inter-patient variability, and differences among ECMO circuits, therapeutic drug monitoring is essential to ensure optimal vancomycin levels. ${ }^{77}$

\section{Carbapenem}

Carbapenems are members of the beta-lactam class of antibiotics and are typically reserved for 
multidrug-resistant bacteria. Beta-lactams, including carbapenems, exert time-dependent killing. These time-dependent antibiotics rely on the amount of time that the antibiotic serum concentration remains above the organism's MIC. ${ }^{78}$ Carbapenems undergo many PK alterations during ECMO, including Vd changes and significant sequestration within the EMCO circuit. ${ }^{79}$ Limited studies are available to describe changes in carbapenem PK parameters in ECMO patients. The high variability of imipenem trough concentrations has been described in a case report of lung transplant patients on VV ECMO who received imipenem 1 gram every six hours. These reports note that utilizing the dosing regimen of 1 gram every six hours achieved 100\% fractional time above the MICs isolated in the patients studied. Patients with resistant organisms and high MICs may require higher doses while patients with decreased renal function may need dose reductions. ${ }^{80}$ The PK of meropenem in ECMO patients has also been investigated. Meropenem use in ECMO patients has been associated with an increased Vd yet a lower clearance. Meropenem clearance has been found to correlate with creatinine clearance and the presence of renal replacement therapy. Ultimately, standard dosing regimens with 1 gram every eight hours are expected to yield routine target concentrations. However, increased doses may be necessary when targeting less susceptible microorganisms. ${ }^{81}$ To further address dosing regimens with resistant organisms, direct comparisons have been drawn between a VV ECMO patient with Enterobacter septicemia receiving meropenem 1 gram every eight hours and a VA ECMO patient with Pseudomonas aeruginosa pneumonia (MIC $2 \mathrm{mg} / \mathrm{L}$ ) and multi-organ failure receiving a high-dose meropenem infusion of 6.5 grams every 24 hours. Similar to previous findings, the standard 1 gram every eight hour regimen was sufficient for organisms with lower MICs, however, increased dosages such as the high-dose infusion were necessary to achieve adequate concentrations for resistant organisms. ${ }^{12}$

\section{Piperacillin/tazobactam}

Many critically ill patients may require treatment with broad-spectrum $\beta$-lactams and, similarly to carbapenems, the PK parameters of $\beta$-lactams during EMCO are not well investigated. Piperacillin/tazobactam is a $\beta$-lactam/ $\beta$-lactamase inhibitor antibiotic with time-dependent activity commonly used for empiric broad-spectrum therapy. Recent investigations using therapeutic drug monitoring of piperacillin/tazobactam concentrations in patients on ECMO therapy demonstrate no significant differences in PK parameters between ECMO and non-ECMO patients. Although limited, this data suggests that dose-adjustments are not required with piperacillin/tazobactam during ECMO therapy. ${ }^{82}$

\section{Aminoglycosides}

Aminoglycosides, including gentamicin, tobramycin and amikacin, are broad-spectrum 
antibiotics with concentration-dependent bactericidal activity. Ensuring adequate peak and trough levels are essential to optimize antimicrobial killing while minimizing toxicity.

Gentamicin PK data derived from neonatal ECMO populations suggest a significantly increased $\mathrm{Vd}$ and half-life as well as a decreased clearance. These PK variations may be a result of gentamicin's hydrophilic profile as well as the decreased renal perfusion seen in neonates, especially during nonpulsatile ECMO therapy. Recommended dosing regimens in this neonatal population are typically $25 \%$

lower than typical dosing in non-ECMO neonates..$^{5,9,14,17,83}$ Although tobramycin has not been separately investigated, due to its comparable pharmacokinetic profile to gentamicin, similar dosing recommendations may be applied. PK parameters and dosage recommendations for gentamicin and tobramycin have not been investigated in adult populations. Given the differences in total body water content and renal clearance between neonates and adults, findings in the neonatal population cannot be extrapolated to adults. Due to the lack of data in adult populations, standard dosing regimens for both gentamicin and tobramycin should be utilized. Given the lack of data in adult patients, close therapeutic monitoring of gentamicin peak and trough levels should be performed.

In contrast to gentamicin, amikacin has been investigated in adult populations. In a single study, ECMO has not been found to significantly impact amikacin peak and trough levels. This data stems from adult VA or VV ECMO patients receiving an amikacin $25 \mathrm{mg} / \mathrm{kg}$ loading dose based on total body weight as an infusion over 30 minutes. It is important to note that this loading dose of $25 \mathrm{mg} / \mathrm{kg}$ was reported to result in insufficient peak serum concentrations in $25 \%$ of patients. Similar to gentamicin, it can be recommended to continue standard amikacin dosing regimens in ECMO patients with therapeutic drug monitoring. ${ }^{84,85}$

\section{Azithromycin}

Azithromycin, a macrolide antibiotic with a long half-life, has been briefly investigated among adult VV ECMO patients with preserved renal function. Patients received standard doses of 500mg intravenously every 24 hours. PK parameters, including maximum and minimum concentrations as well as the area under the curve, were similar to non-ECMO patients. Furthermore, the assessment of blood samples collected at steady state revealed a similar clearance but a decreased $\mathrm{Vd}$ as compared to healthy volunteers. Collectively, these results suggest that ECMO does not significantly impact the pharmacokinetics of azithromycin. ${ }^{86}$

\section{Linezolid}


Linezolid is a protein synthesis inhibitor which is typically reserved for resistant gram positive infections, such as vancomycin-resistant Enterococcus (VRE) and specific cases of methicillin-resistant Staphylococcus aureus (MRSA). Due to its high pulmonary penetration, linezolid is a reasonable therapeutic option for pneumonia caused by these resistant organisms. Only one report investigating linezolid plasma concentrations in patients on ECMO. This report investigated linezolid PK parameters in three adult patients being treated for MRSA pneumonia. S. aureus MICs ranged from $1 \mathrm{mg} / \mathrm{L}$ to $4 \mathrm{mg} / \mathrm{L}$ and each patient received standard doses of linezolid 600mg IV every 12 hours. Pharmacokinetic analyses demonstrated that standard doses were able to achieve adequate AUC/MIC ratios $>80$ only when the MIC was $\leq 1 \mathrm{mg} / \mathrm{L} .{ }^{87}$ Although limited data is available, it is recommended to continue standard dosing when the MIC is $\leq 1 \mathrm{mg} / \mathrm{L}$. In instances where the MIC is $>1 \mathrm{mg} / \mathrm{L}$, previous studies suggest the use of prolonged or continuous infusions as well as increased dosages of linezolid.

\section{$\underline{\text { Tigecylcline }}$}

Tigecycline, a glycylcycline antibiotic typically reserved for resistant infections, has a very large $\mathrm{Vd}$, and is eliminated primarily unchanged in feces and urine. To date, there is only one case report investigating tigecycline PK in ECMO patients. Tigecycline treatment has been described in an adult VV ECMO patient with a persistent S. epidermidis pulmonary infection in the setting of vancomycin resistance. This specific patient received standard tigecycline doses of $50 \mathrm{mg}$ IV twice daily. Though measurements of plasma and tracheal aspirate concentrations, it was determined that ECMO does not have an impact on tigecycline pharmacokinetics. ${ }^{88}$ The available data suggest standard tigecycline doses may be used in ECMO patients.

\section{Oseltamivir}

Oseltamivir, an antiviral medication, is indicated for the treatment and prophylaxis of influenza. The standard dose of oseltamivir for the treatment of influenza is $75 \mathrm{mg}$ administered nasogastrically or nasoenterically every 12 hours. Similar to the absorption of parenteral medications through the ECMO circuit, the absorption of enteral medications is also variable. Limited data suggests oseltamivir is adequately absorbed when enterally administered during ECMO.$^{89,90}$ Pharmacokinetic parameters of oseltamivir administered nasogastrically or nasoenterically in ECMO patients include decreased clearance and increased $\mathrm{Vd}$ compared to healthy adult patients. While specific dosage adjustments for ECMO are not necessary, oseltamivir should still be adjusted for renal impairment. ${ }^{91}$ The effects of CVVHD in addition to ECMO therapy have also been investigated. Pharmacokinetics of oseltamivir and oseltamivir carboxylate in patients concurrently on CVVHD and ECMO revealed no substantial differences between pre- and post-ECMO oxygenator plasma concentrations. Although ECMO may not 
extensively contribute to changes in oseltamivir PK, CVVHD significantly affects its clearance. ${ }^{92}$ Standard doses of oseltamivir in patients on CVVHD have been associated with drug accumulation. Thus, decreased oseltamivir doses are recommended in patients with renal failure as well as patients requiring CVVHD. No specific dosage adjustments are necessary during ECMO therapy. ${ }^{91,93}$

\section{$\underline{\text { Ribavirin }}$}

Ribavirin, an anti-viral medication, has been utilized for the treatment of disseminated adenovirus in neonates requiring hemofiltration. Doses of $20 \mathrm{mg} / \mathrm{kg} /$ day intravenously have demonstrated low plasma concentrations at steady state despite negative viral cultures 48 hours post ribavirin initiation. ${ }^{94}$ Additional studies in the adult population have yet to be conducted. Standard dosing recommendations may be employed in adult ECMO patients, caution should be exercised due to the lack of data and low plasma concentrations observed in neonates.

\section{Antifungals:}

\section{$\underline{\text { Amphotericin B }}$}

Amphotericin B is a polyene antifungal agent which binds to ergosterol in the fungal cell wall leading to alterations in cell membrane permeability. Only one case report of IV amphotericin B use in one 15-year-old patient on VA ECMO with respiratory failure secondary to Blastomyces dermatitidis pneumonia has been reported. The specific formulation of IV amphotericin B was not specified. The patient received $25 \mathrm{mg}$ intravenously over four hours on the first day of therapy followed by two $100 \mathrm{mg}$ $(1 \mathrm{mg} / \mathrm{kg}$ ) doses separated by nine hours on day two, and $100 \mathrm{mg}$ over four hours daily $(1 \mathrm{mg} / \mathrm{kg} / \mathrm{day})$ starting day three. Analysis of the patient's amphotericin B peak and trough levels indicate that ECMO did not contribute to $\mathrm{Vd}$ changes affecting amphotericin B therapy. Based upon this limited data set, no specific dosing adjustments need to be made in ECMO patients. ${ }^{95,96}$

\section{Echinocandins/Azoles}

Fungal infections in intensive care units (ICUs) have risen significantly in the past several decades. Broad spectrum antifungal agents such as caspofungin and voriconazole may be used as empiric therapy for specific at-risk ICU patient populations. Ex vivo studies in blood-primed ECMO circuits have demonstrated significant voriconazole losses up to $71 \% .{ }^{97}$ Due to this anticipated voriconazole sequestration, voriconazole doses in an in vivo study were increased from $280 \mathrm{mg}(4 \mathrm{mg} / \mathrm{kg})$ twice daily to $400 \mathrm{mg}$ ( $6 \mathrm{mg} / \mathrm{kg}$ ) twice daily. Drug concentration obtained two days following this dose increase reflected supratherapeutic levels with troughs $>10 \mathrm{mg} / \mathrm{mL}$ and peaks of $\sim 15 \mathrm{mg} / \mathrm{mL}$. The 
analysis of caspofungin peaks and troughs in these patients suggest that caspofungin is not sequestered by the ECMO circuit. ${ }^{98}$ Comparatively, an additional case report notes a patient to receive standard doses of voriconazole ( $6 \mathrm{mg} / \mathrm{kg}$ twice daily on day 1 followed by $4 \mathrm{mg} / \mathrm{kg}$ twice daily) and caspofungin (70 mg on day 1 followed by $50 \mathrm{mg} /$ day). Blood concentrations collected for both voriconazole and caspofungin revealed undetectable circulating levels. ${ }^{96} \mathrm{It}$ is difficult to draw a conclusion based on these two reports. Voriconazole has demonstrated significant inter-patient variability even among non-ECMO patients. ${ }^{99}$ Additional studies elucidating the effect of voriconazole PK in ECMO patients are necessary. Therapeutic drug monitoring should be conducted in all ECMO patients on voriconazole therapy to ensure efficacy and to minimize toxicity. Data suggests that standard-dosed caspofungin may be adequate in ECMO patients. In light of limited data, dosing recommendations is provisional for these agents.

\section{Antituberculosis Agents}

A case report of one adult patient on VV ECMO documents subtherapeutic levels of isoniazid, rifampin, ethambutol, and pyrazinamide despite standard dosing regimens. In order to achieve target plasma concentrations, the patient required conversion from oral to intravenous administration routes and doses of $23 \mathrm{mg} / \mathrm{kg} / \mathrm{d}$ of rifampin (compared to the standard dose of $10 \mathrm{mg} / \mathrm{kg} / \mathrm{d}$ ). Double the standard doses of pyrazinamide and ethambutol were also necessary. ${ }^{63}$ The pharmacokinetic parameters of ethambutol and rifampin have also been investigated in patients on ECMO and extended daily dialysis. Contrary to the case report previously described, results from the PK analysis conclude that the ECMO membrane did not have an effect on the removal of either medication. However, extended daily dialysis removed a considerable amount of both medications from circulating volume. Ethambutol doses between $1000-2000 \mathrm{mg} /$ day are suggested for patients on renal replacement therapy to achieve target peak levels. ${ }^{100}$ These conflicting data supports the use of therapeutic drug monitoring in ECMO patients to ensure target concentrations.

\section{Conclusion:}

Pharmacokinetic changes resulting from ECMO and their clinical impact are not yet fully characterized for most of the drugs used in critically ill patients. Given the limited patient population, the database of PK studies in ECMO patients is largely reliant upon on in vitro data or case studies. Although limited, available data can assist health care providers in tailoring dosing regimens for adult ECMO patients. Whenever possible, therapeutic drug monitoring should be conducted to ensure efficacy while minimizing toxicity. 
1. Boucher BA, Wood GC, Swanson JM. Pharmacokinetic changes in critical illness. Crit Care Clin. 2006;22(2):255-271. doi: http://dx.doi.org/10.1016/i.ccc.2006.02.011.

2. Vilay AM, Churchwell MD, Mueller BA. Clinical review: Drug metabolism and nonrenal clearance in acute kidney injury. Crit Care. 2008;12(6):235. doi: cc7093 [pii].

3. Schmith VD, Foss JF. Inflammation: Planning for a source of pharmacokinetic/pharmacodynamic variability in translational studies. Clinical Pharmacology \& Therapeutics. 2010;87(4):488-491. doi: 10.1038/clpt.2009.258.

4. Smith BS, Yogaratnam D, Levasseur-Franklin KE, Forni A, Fong J. Introduction to drug pharmacokinetics in the critically III patient. Chest. 2012;141(5):1327-1336. doi: http://dx.doi.org/10.1378/chest.11-1396.

5. Mousavi S., Levcovich B., Mojtahedzadeh M. A systematic review on pharmacokinetic changes in critically ill patients: Role of extracorporeal membrane oxygenation. DARU Journal of Pharmaceutical Sciences. 2011;19(5). http://daru.tums.ac.ir/index.php/daru/article/view/409.

6. Hadidi E, Mojtahedzadeh M, Rouini MR, Eftekhar B, Abdollahi M, Najafi A, Khajavi MR, Rezaee S, Ghaffari R, Afshar M. The evaluation of the possible effect of positive end expiratory pressure (peep) on pharmacokinetics of phenytoin in patients with acute brain injury under mechanical ventilation. DARU Journal of Pharmaceutical Sciences. 2005;13(2). http://daru.tums.ac.ir/index.php/daru/article/view/238.

7. Anderson HL, Coran AG, Drongowski RA, Ha HJ, Bartlett RH. Extracellular fluid and total body water changes in neonates undergoing extracorporeal membrane oxygenation. Journal of Pediatric Surgery. 1992;27(8):1003-1008. doi: http://dx.doi.org/10.1016/0022-3468(92)90547-K.

8. Perkins MW, Dasta JF, Dehaven B. Physiologic implications of mechanical ventilation on pharmacokinetics. DICP. 1989;23(4):316-323. 
http://journals.sagepub.com/doi/abs/10.1177/106002808902300408. doi:

$10.1177 / 106002808902300408$.

9. Shekar K, Roberts JA, Welch S, et al. Antibiotic, sedative and analgesic pharmacokinetics during extracorporeal membrane oxygenation: A multi-centre study to optimise drug therapy during ECMO. BMC Anesthesiol. 2012;12. http://dx.doi.org/10.1186/1471-2253-12-29. doi: 10.1186/1471-2253-12-29.

10. Buck ML. Pharmacokinetic changes during extracorporeal membrane oxygenation. Clin Pharmacokinet. 2003;42(5):403-417. http://dx.doi.org/10.2165/00003088-200342050-00001. doi: 10.2165/00003088-200342050-00001.

11. Mehta NM, Halwick DR, Dodson BL, Thompson JE, Arnold JH. Potential drug sequestration during extracorporeal membrane oxygenation: Results from an ex vivo experiment. Intensive Care Med. 2007;33 (6): 1018-1024. http://dx.doi.org/10.1007/s00134-007-0606-2. doi: 10.1007/s00134-007-06062.

12. Shekar K, Roberts JA, Ghassabian S, et al. Altered antibiotic pharmacokinetics during extracorporeal membrane oxygenation: Cause for concern? J Antimicrob Chemother. 2013;68(3):726-727. http://dx.doi.org/10.1093/jac/dks435.

13. Rosen DA, Rosen KR, Silvasi DL. In vitro variability in fentanyl absorption by different membrane oxygenators. Journal of Cardiothoracic Anesthesia. 1990;4(3):332-335. doi: http://dx.doi.org/10.1016/0888-6296(90)90041-D.

14. Dagan O, Klein J, Gruenwald C, Bohn D, Barker G, Koren G. Preliminary studies of the effects of extracorporeal membrane oxygenator on the disposition of common pediatric drugs. Ther Drug Monit. $1993 ; 15(4): 263-266$. 
15. Wildschut ED, Ahsman MJ, Allegaert K, Mathot RAA, Tibboel D. Determinants of drug absorption in different ECMO circuits. Intensive Care Med. 2010;36(12):2109-2116.

http://www.ncbi.nlm.nih.gov/pmc/articles/PMC2981740/. doi: 10.1007/s00134-010-2041-z.

16. Preston TJ, Hodge AB, Riley JB, Leib-Sargel C, Nicol KK. In vitro drug adsorption and plasma free hemoglobin levels associated with hollow fiber oxygenators in the extracorporeal life support (ECLS) circuit. J Extra Corpor. 2007;39 (4):234-237. http://www.ncbi.nlm.nih.gov/pmc/articles/PMC4680688/.

17. Bhatt-Meht V, Annich G. Sedative clearance during extracorporeal membrane oxygenation.

Perfusion. 2005;20. http://dx.doi.org/10.1191/0267659105pf827oa. doi: 10.1191/0267659105pf827oa.

18. Shekar K, Roberts JA, Mcdonald Cl, et al. Protein-bound drugs are prone to sequestration in the extracorporeal membrane oxygenation circuit: Results from an ex vivo study. Critical Care. 2015;19(1):164. http://dx.doi.org/10.1186/s13054-015-0891-z. doi: 10.1186/s13054-015-0891-z.

19. Shekar K, Fraser JF, Smith MT, Roberts JA. Pharmacokinetic changes in patients receiving extracorporeal membrane oxygenation. J Crit Care. 2012;27.

http://dx.doi.org/10.1016/j.jcrc.2012.02.013. doi: 10.1016/j.jcrc.2012.02.013.

20. Mulla H, Lawson G, von Anrep C, et al. In vitro evaluation of sedative drug losses during extracorporeal membrane oxygenation. Perfusion. 2000;15(1):21-26.

http://journals.sagepub.com/doi/abs/10.1177/026765910001500104. doi:

$10.1177 / 026765910001500104$.

21. Paden ML, Conrad SA, Rycus PT, Thiagarajan RR, ELSO Registry. Extracorporeal life support organization registry report 2012. ASAIO J. 2013;59(3):202-210. doi: 10.1097/MAT.0b013e3182904a52 [doi]. 
22. Roos JF, Bulitta J, Lipman J, Kirkpatrick CMJ. Pharmacokinetic-pharmacodynamic rationale for cefepime dosing regimens in intensive care units. J Antimicrob Chemother. 2006;58(5):987-993. http://dx.doi.org/10.1093/jac/dkl349.

23. Johnston N, Wait M, Huber L. Argatroban in adult extracorporeal membrane oxygenation. J Extra Corpor Technol. 2002;34(4):281-284.

24. Buscher H, Vaidiyanathan SF, Al-Soufi SF, et al. Sedation practice in veno-venous extracorporeal membrane oxygenation: An international survey. ASAIO journal (American Society for Artificial Internal Organs : 1992) JID - 9204109. 0613(1538-943).

25. DeGrado JR, Hohlfelder B, Ritchie BM, Anger KE, Reardon DP, Weinhouse GL. Evaluation of sedatives, analgesics, and neuromuscular blocking agents in adults receiving extracorporeal membrane oxygenation. J Crit Care. 2017;37:1-6. doi: http://dx.doi.org/10.1016/i.jcrc.2016.07.020.

26. Erstad BL, Puntillo K, Gilbert HC, et al. Pain management principles in the critically ill. Chest. 2009;135(4):1075-1086. doi: http://dx.doi.org/10.1378/chest.08-2264.

27. Barr J, FAU FG, Puntillo KF, et al. Clinical practice guidelines for the management of pain, agitation, and delirium in adult patients in the intensive care unit. Critical care medicine JID - 0355501. 0304.

28. Satyapriya SV, Lyaker ML, Rozycki AJ, Papadimos,. Sedation, analgesia delirium in the ECMO patient. In: Extracorporeal membrane oxygenation - advances in therapy. Rijeka: InTech; 2016:Ch. 0. http://dx.doi.org/10.5772/64249. 10.5772/64249.

29. Dagan O, Klein JF, Bohn DF, Koren G. Effects of extracorporeal membrane oxygenation on morphine pharmacokinetics in infants. Critical care medicine JID - 0355501. 0811. 
30. Peters JWB, Anderson BJ, Simons SHP, Uges DRA, Tibboel D. Morphine pharmacokinetics during venoarterial extracorporeal membrane oxygenation in neonates. Intensive Care Med. 2005;31(2):257263. http://dx.doi.org/10.1007/s00134-004-2545-5. doi: 10.1007/s00134-004-2545-5.

31. Subramaniam K, Subramaniam B FAU - Steinbrook, Richard,A., Steinbrook RA. Ketamine as adjuvant analgesic to opioids: A quantitative and qualitative systematic review. Anesthesia and analgesia JID 1310650. 0823.

32. Tellor B, Shin N, Graetz TJ, Avidan MS. Ketamine infusion for patients receiving extracorporeal membrane oxygenation support: A case series version 1; referees: 2 approved]. F1000Research. 2015;4(16). http://f1000r.es/4yj. doi: 10.12688/f1000research.6006.1.

33. Dzierba AL, Brodie D, Bacchetta M, et al. Ketamine use in sedation management in patients receiving extracorporeal membrane oxygenation. Intensive Care Med. 2016;42(11):1822-1823. http://dx.doi.org/10.1007/s00134-016-4519-9. doi: 10.1007/s00134-016-4519-9.

34. Shekar K, Roberts JA, Welch S, Buscher H, Rudham S, Burrows F. ASAP ECMO: Antibiotic, sedative and analgesic pharmacokinetics during extracorporeal membrane oxygenation: A multi-centre study to optimise drug therapy during ECMO. BMC Anesthesiol. 2012;12. http://dx.doi.org/10.1186/1471-225312-29. doi: 10.1186/1471-2253-12-29.

35. Hynynen M, Hammaren E, Rosenberg PH. Propofol sequestration within the extracorporeal circuit. Canadian Journal of Anaesthesia. 1994;41(7):583. http://dx.doi.org/10.1007/BF03009997. doi: 10.1007/BF03009997.

36. Riker RR, Shehabi Y, Bokesch PM, et al. Dexmedetomidine vs midazolam for sedation of critically ill patients: A randomized trial. JAMA. 2009;301(5):489-499. http://dx.doi.org/10.1001/jama.2009.56. 
37. Wagner D, Pasko D, Phillips K, Waldvogel J, Annich G. In vitro clearance of dexmedetomidine in extracorporeal membrane oxygenation. Perfusion. 2013;28(1):40-46.

http://journals.sagepub.com/doi/abs/10.1177/0267659112456894. doi: 10.1177/0267659112456894.

38. Hraiech S, Dizier S, Papazian L. The use of paralytics in patients with acute respiratory distress syndrome. Clin Chest Med.2014;35(4):753-763. http://dx.doi.org/10.1016/j.ccm.2014.08.012. doi: 10.1016/j.ccm.2014.08.012.

39. Tulman DB, Stawicki SPA, Whitson BA, et al. Veno-venous ECMO: A synopsis of nine key potential challenges, considerations, and controversies. BMC Anesthesiology. 2014;14:65-65.

http://www.ncbi.nIm.nih.gov/pmc/articles/PMC4126084/. doi: 10.1186/1471-2253-14-65.

40. Greenberg SB, Vender J. The use of neuromuscular blocking agents in the ICU: Where are we now? Critical care medicine JID - 0355501. 0620.

41. Latronico N, Guarneri B. Critical illness myopathy and neuropathy. Minerva anestesiologica JID 0375272.0915.

42. Protti A, L'Acqua C, Panigada M. The delicate balance between pro-(risk of thrombosis) and anti-(risk of bleeding) coagulation during extracorporeal membrane oxygenation. Annals of Trans/ational Medicine. 2016;4(7):139. http://www.ncbi.nIm.nih.gov/pmc/articles/PMC4842390/. doi: 10.21037/atm.2016.03.06.

43. Oliver WC. Anticoagulation and coagulation management for ECMO. Seminars in Cardiothoracic and Vascular Anesthesia. 2009;13(3):154-175. http://journals.sagepub.com/doi/abs/10.1177/1089253209347384. doi: 10.1177/1089253209347384.

44. Muntean W. Coagulation and anticoagulation in extracorporeal Membrane Oxygenation. Artif Organs. 1999;23(11):979-983. doi: 10.1046/j.1525-1594.1999.06451.x. 
45. Trudzinski FC, Minko P, Rapp D, et al. Runtime and aPTT predict venous thrombosis and thromboembolism in patients on extracorporeal membrane oxygenation: A retrospective analysis. Annals of intensive care JID - 101562873 PMC - PMC4949188 OID - NLM: PMC4949188 EDAT2016/07/20 06:00 MHDA- 2016/07/20 06:01 CRDT- 2016/07/20 06:00 PHST- 2016/01/27 received] PHST- 2016/07/04 accepted] AID - 10.1186/s13613-016-0172-2 doi] AID -(TRUNCATED). 0719.

46. Malfertheiner MV, Philipp A, Lubnow M, et al. Hemostatic changes during extracorporeal membrane oxygenation: A prospective randomized clinical trial comparing three different extracorporeal membrane oxygenation systems. Crit Care Med. 2016;44(4):747-754. doi: 10.1097/CCM.0000000000001482 [doi].

47. Bembea MM, Annich G, Rycus P, Oldenburg G, Berkowitz I, Pronovost P. Variability in anticoagulation management of patients on extracorporeal membrane oxygenation: An international survey. Pediatric critical care medicine : a journal of the Society of Critical Care Medicine and the World Federation of Pediatric Intensive and Critical Care Societies. 2013;14(2):e77-e77.

http://www.ncbi.nlm.nih.gov/pmc/articles/PMC3567253/. doi: 10.1097/PCC.0b013e31827127e4.

48. Sklar MC, Sy E, Lequier L, Fan E, Kanji HD. Anticoagulation practices during venovenous extracorporeal membrane oxygenation for respiratory failure. A systematic review. Annals of the American Thoracic Society JID - 101600811 OTO - NOTNLM. 1003.

49. Lamarche Y, Chow B, Bedard A, et al. Thromboembolic events in patients on extracorporeal membrane oxygenation without anticoagulation. Innovations (Phila). 2010;5(6):424-429. doi: 10.1097/IMI.0b013e3182029a83 [doi].

50. Krueger K, Schmutz A, Zieger B, Kalbhenn J. Venovenous extracorporeal membrane oxygenation with prophylactic subcutaneous anticoagulation only: An observational study in more than 60 patients. Artif Organs. 2017;41(2):186-192. doi: 10.1111/aor.12737. 
51. Wen PH, Chan WH, Chen YC, Chen YL, Chan CP, Lin PY. Non-heparinized ECMO serves a rescue method in a multitrauma patient combining pulmonary contusion and nonoperative internal bleeding: $\mathrm{A}$ case report and literature review. World J Emerg Surg. 2015;10:10.1186/s13017-015-0006-9. doi: 6 [pii].

52. Arlt M, Philipp A, Voelkel S, et al. Extracorporeal membrane oxygenation in severe trauma patients with bleeding shock. Resuscitation. 2010;81(7):804-809. doi: 10.1016/j.resuscitation.2010.02.020 [doi].

53. Chung YS, Cho DY, Sohn DS, et al. Is stopping heparin safe in patients on extracorporeal membrane oxygenation treatment? ASAIO J. 2017;63(1):32-36. doi: 10.1097/MAT.0000000000000442 [doi].

54. Koster A, Weng Y, Bottcher W, Gromann T, Kuppe H, Hetzer R. Successful use of bivalirudin as anticoagulant for ECMO in a patient with acute HIT. Ann Thorac Surg. ;83(5):1865-1867. http://dx.doi.org/10.1016/j.athoracsur.2006.11.051. doi: 10.1016/j.athoracsur.2006.11.051.

55. Ranucci M, Ballotta A, Kandil H, et al. Bivalirudin-based versus conventional heparin anticoagulation for postcardiotomy extracorporeal membrane oxygenation. Critical Care. 2011;15(6):R275-R275. http://www.ncbi.nIm.nih.gov/pmc/articles/PMC3388709/. doi: 10.1186/cc10556.

56. Pieri M, Agracheva N, Bonaveglio E, et al. Bivalirudin versus heparin as an anticoagulant during extracorporeal membrane oxygenation: A case-control study. J Cardiothorac Vasc Anesth. 2013;27(1):30-34. doi: http://dx.doi.org/10.1053/i.jvca.2012.07.019.

57. Young G, Yonekawa KE, Nakagawa P, Nugent DJ. Argatroban as an alternative to heparin in extracorporeal membrane oxygenation circuits. Perfusion. 2004;19(5):283-288. http://dx.doi.org/10.1191/0267659104pf759oa. doi: 10.1191/0267659104pf759oa. 58. Kawada T, Kitagawa H, Hoson M, Okada Y, Shiomura J. Clinical application of argatroban as an alternative anticoagulant for extracorporeal circulation. Hematol Oncol Clin North Am. 2000;14(2):445457. doi: http://dx.doi.org.proxy1.lib.tju.edu/10.1016/S0889-8588(05)70144-1. 
59. Beiderlinden M, Treschan T, Görlinger K, Peters J. Argatroban in extracorporeal membrane oxygenation. Artif Organs. 2007;31(6):461-465. doi: 10.1111/j.1525-1594.2007.00388.x.

60. Potter KE, Raj A, Sullivan JE. Argatroban for anticoagulation in pediatric patients with heparininduced thrombocytopenia requiring extracorporeal life support. J Pediatr Hematol Oncol. 2007;29(4):265-268. doi: 10.1097/MPH.0b013e3180463626 [doi].

61. Phillips MR, Khoury AI, Ashton RF, Cairns BA, Charles AG. The dosing and monitoring of argatroban for heparin-induced thrombocytopenia during extracorporeal membrane oxygenation: A word of caution. Anaesth Intensive Care. 2014;42(1):97-98. doi: 20130550 [pii].

62. Sanfilippo F, Asmussen S, Maybauer DM, et al. Bivalirudin for alternative anticoagulation in extracorporeal membrane oxygenation. J Intensive Care Med. 2016:0885066616656333. http://dx.doi.org/10.1177/0885066616656333. doi: 10.1177/0885066616656333.

63. Kim HS, FAU LE, Cho YJ. Insufficient serum levels of antituberculosis agents during venovenous extracorporeal membrane oxygenation therapy for acute respiratory distress syndrome in a patient with miliary tuberculosis. ASAIO journal (American Society for Artificial Internal Organs : 1992) JID - 9204109. 1104(1538-943).

64. Glauber M, Szefner J, Senni M, et al. Reduction of haemorrhagic complications during mechanically assisted circulation with the use of a multi-system anticoagulation protocol. Int J Artif Organs. 1995;18(10):649-655.

65. Bein T, Zimmermann M, Philipp A, et al. Addition of acetylsalicylic acid to heparin for anticoagulation management during pumpless extracorporeal lung assist. ASAIO J. 2011;57(3):164-168. doi:

10.1097/MAT.0b013e318213f9e0 [doi]. 
66. Esper SA, Bermudez C, Dueweke EJ, et al. Extracorporeal membrane oxygenation support in acute coronary syndromes complicated by cardiogenic shock. Catheter Cardiovasc Interv. 2015;86 Suppl 1:S4550. doi: $10.1002 /$ ccd.25871 [doi].

67. Barthelemy O, Silvain J, Brieger D, et al. Bleeding complications in primary percutaneous coronary intervention of ST-elevation myocardial infarction in a radial center. Catheter Cardiovasc Interv. 2012;79(1):104-112. doi: 10.1002/ccd.23164 [doi].

68. Szefner J. Control and treatment of hemostasis in cardiovascular surgery. the experience of la pitie hospital with patients on total artificial heart. Int J Artif Organs. 1995;18(10):633-648.

69. Staudacher DL, Biever PM, Benk C, Ahrens I, Bode C, Wengenmayer T. Dual antiplatelet therapy (DAPT) versus no antiplatelet therapy and incidence of major bleeding in patients on venoarterial extracorporeal membrane oxygenation. PLoS One. 2016;11(7):e0159973. doi:10.1371/journal.pone.0159973. doi: 10.1371/journal.pone.0159973 [doi].

70. Buck ML. Pharmacokinetic changes during extracorporeal membrane oxygenation: Implications for drug therapy of neonates. Clin Pharmacokinet. 2003;42. http://dx.doi.org/10.2165/00003088200342050-00001. doi: 10.2165/00003088-200342050-00001.

71. Sherwin J, Heath T, Watt K. Pharmacokinetics and dosing of anti-infective drugs in patients on extracorporeal membrane oxygenation: A review of the current literature. Clin Ther. 2016;38(9):19761994. doi: $\underline{\text { http://dx.doi.org/10.1016/i.clinthera.2016.07.169. }}$

72. Brown DL, Lalla CD, Masselink AJ. AUC versus peak-trough dosing of vancomycin: Applying new pharmacokinetic paradigms to an old drug. Ther Drug Monit. 2013;35(4):443-449. doi:

10.1097/FTD.0b013e31828b2a50 [doi]. 
73. Rybak MJ, Lomaestro BM, Rotschafer JC, et al. Vancomycin therapeutic guidelines: A summary of consensus recommendations from the infectious diseases society of america, the american society of health-system pharmacists, and the society of infectious diseases pharmacists. Clin Infect Dis. 2009;49. http://dx.doi.org/10.1086/600877. doi: 10.1086/600877.

74. Moore JN, Healy JR, Thoma BN, et al. A population pharmacokinetic model for vancomycin in adult patients receiving extracorporeal membrane oxygenation therapy. CPT: Pharmacometrics \& Systems Pharmacology. 2016;5(9):495-502. http://www.ncbi.nlm.nih.gov/pmc/articles/PMC5036424/. doi: 10.1002/psp4.12112.

75. Donadello K, Roberts JA, Cristallini S, et al. Vancomycin population pharmacokinetics during extracorporeal membrane oxygenation therapy: A matched cohort study. Critical Care. 2014;18(6):632. http://dx.doi.org/10.1186/s13054-014-0632-8. doi: 10.1186/s13054-014-0632-8.

76. Park SJ, Yang JH, Park HJ, et al. Trough concentrations of vancomycin in patients undergoing extracorporeal membrane oxygenation. PLOS ONE. 2015;10(11):e0141016. http://www.ncbi.nlm.nih.gov/pmc/articles/PMC4636270/. doi: 10.1371/journal.pone.0141016.

77. Wu C, Shen L, Hsu L, Ko W, Wu FL. Pharmacokinetics of vancomycin in adults receiving extracorporeal membrane oxygenation. J Formosan Med Assoc. 2016;115(7):560-570. doi: http://dx.doi.org/10.1016/j.jfma.2015.05.017.

78. Levison ME, Levison JH. Pharmacokinetics and pharmacodynamics of antibacterial agents. Infect Dis Clin North Am. 2009;23(4):791-vii. doi: 10.1016/j.idc.2009.06.008 [doi].

79. Roberts JA, Lipman J. Pharmacokinetic issues for antibiotics in the critically ill patient. Crit Care Med. 2009;37. http://dx.doi.org/10.1097/CCM.0b013e3181961bff. doi: 10.1097/CCM.0b013e3181961bff. 
80. Welsch C, Augustin P, Allyn J, Massias L, Montravers P, Allou N. Alveolar and serum concentrations of imipenem in two lung transplant recipients supported with extracorporeal membrane oxygenation.

Transplant Infectious Disease. 2015;17(1):103-105. doi: 10.1111/tid.12327.

81. Shekar K, Fraser JF, Taccone FS, et al. The combined effects of extracorporeal membrane oxygenation and renal replacement therapy on meropenem pharmacokinetics: A matched cohort study. Critical Care. 2014;18(6):565. http://www.ncbi.nlm.nih.gov/pmc/articles/PMC4302127/. doi:

10.1186/s13054-014-0565-2.

82. Donadello K, Antonucci E, Cristallini S, et al. B-lactam pharmacokinetics during extracorporeal membrane oxygenation therapy: A case-control study. Int J Antimicrob Agents. 2015;45(3):278-282. doi: http://dx.doi.org/10.1016/j.ijantimicag.2014.11.005.

83. Buck ML. Pharmacokinetic changes during extracorporeal membrane oxygenation: Implications for drug therapy of neonates. Clin Pharmacokinet. 2003;42. http://dx.doi.org/10.2165/00003088200342050-00001. doi: 10.2165/00003088-200342050-00001.

84. G\'elisse E, Neuville M, de Montmollin E, et al. Extracorporeal membrane oxygenation (ECMO) does not impact on amikacin pharmacokinetics: A case--control study. Intensive Care Med. 2016;42(5):946948. http://dx.doi.org/10.1007/s00134-016-4267-x. doi: 10.1007/s00134-016-4267-x".

85. de Montmollin E, Bouadma L, Gault N, et al. Predictors of insufficient amikacin peak concentration in critically ill patients receiving a $25 \mathrm{mg} / \mathrm{kg}$ total body weight regimen. Intensive Care Med. 2014;40(7):998-1005. doi: 10.1007/s00134-014-3276-x [doi].

86. Turner RB, Rouse S, Elbarbry F, Wanek S, Grover V, Chang E. Azithromycin pharmacokinetics in adults with acute respiratory distress syndrome undergoing treatment with extracorporeal-membrane 
oxygenation. Ann Pharmacother. 2016;50(1):72-73. http://dx.doi.org/10.1177/1060028015612105. doi: 10.1177/1060028015612105.

87. De Rosa FG, Corcione S, Baietto L, et al. Pharmacokinetics of linezolid during extracorporeal membrane oxygenation. Int J Antimicrob Agents. 2013;41(6):590-591. doi:

10.1016/j.ijantimicag.2013.01.016 [doi].

88. Veinstein A, Debouverie O, GrÃ@goire N, et al. Lack of effect of extracorporeal membrane oxygenation on tigecycline pharmacokinetics. J Antimicrob Chemother. 2012;67(4):1047-1048. http://dx.doi.org/10.1093/jac/dkr550.

89. Pettignano R, Heard MF, Davis RF, Labuz MF, Hart M. Total enteral nutrition versus total parenteral nutrition during pediatric extracorporeal membrane oxygenation. Critical care medicine JID - 0355501. 0226.

90. Flordelis Lasierra JL, Perez-Vela JL, Montejo Gonzalez JC. Enteral nutrition in the hemodynamically unstable critically ill patient. Medicina intensiva JID - 9207689. 0110.

91. Mulla H, Peek GJ, Harvey C, Westrope C, Kidy Z, Ramaiah R. Oseltamivir pharmacokinetics in critically ill adults receiving extracorporeal membrane oxygenation support. Anaesth Intensive Care. 2013;41.

92. Eyler RF, Heung M, Pleva M, et al. Pharmacokinetics of oseltamivir and oseltamivir carboxylate in critically ill patients receiving continuous venovenous hemodialysis and/or extracorporeal membrane oxygenation. Pharmacotherapy: The Journal of Human Pharmacology and Drug Therapy. 2012;32(12):1061-1069. doi: 10.1002/phar.1151.

93. Lemaitre F, FAU LC, Roullet-Renoleau FF, et al. Impact of extracorporeal membrane oxygenation and continuous venovenous hemodiafiltration on the pharmacokinetics of oseltamivir carboxylate in critically ill patients with pandemic (H1N1) influenza. Therapeutic drug monitoring JID - 7909660. 0711. 
94. Aebi C, Headrick CL, McCracken GH, Jr., Lindsay CA. Intravenous ribavirin therapy in a neonate with disseminated adenovirus infection undergoing extracorporeal membrane oxygenation:

Pharmacokinetics and clearance by hemofiltration. J Pediatr. ;130(4):612-615.

http://dx.doi.org/10.1016/S0022-3476(97)70246-4. doi: 10.1016/S0022-3476(97)70246-4.

95. Hertzog J, Brackett E, Sale M, Hauser G, Dalton H. Amphotericin B pharmacokinetics during extracorporea/ membrane oxygenation: A case report. The Journal of extra-corporeal technology. 1996;28(2):94.

96. Ruiz S, Papy E, Da Silva D, et al. Potential voriconazole and caspofungin sequestration during extracorporeal membrane oxygenation. Intensive Care Med. 2008;35(1):183. http://dx.doi.org/10.1007/s00134-008-1269-3. doi: 10.1007/s00134-008-1269-3.

97. Mehta NM, Halwick DR, Dodson BL, Thompson JE, Arnold JH. Potential drug sequestration during extracorporeal membrane oxygenation: Results from an ex vivo experiment. Intensive Care Med. 2007;33(6):1018-1024. http://dx.doi.org/10.1007/s00134-007-0606-2. doi: 10.1007/s00134-007-0606-2.

98. Spriet I, Annaert P, Meersseman P, et al. Pharmacokinetics of caspofungin and voriconazole in critically ill patients during extracorporeal membrane oxygenation. J Antimicrob Chemother. 2009;63(4):767-770. http://dx.doi.org/10.1093/jac/dkp026.

99. Saini L, Seki JT, Kumar D, et al. Serum voriconazole level variability in patients with hematological malignancies receiving voriconazole therapy. Can J Infect Dis Med Microbiol. 2014;25(5):271-276. doi: idmm-25-271 [pii].

100. Strunk A, Ciesek S, Schmidt JJ, et al. Single- and multiple-dose pharmacokinetics of ethambutol and rifampicin in a tuberculosis patient with acute respiratory distress syndrome undergoing extended daily 
dialysis and ECMO treatment. International Journal of Infectious Diseases. 2016;42:1-3. doi: http://dx.doi.org/10.1016/i.iiid.2015.10.018. 
Figure 1: ECMO Configuration

\section{ECMO Circuit}

$\left.\begin{array}{c}\text { Blood } \\ \text { extracted from } \\ \text { venous system }\end{array}>\begin{array}{c}\text { Blood } \\ \text { circulated into } \\ \text { oxygenator }\end{array}\right\rangle \begin{gathered}\text { Oxygen } \\ \text { saturation and } \\ \text { CO2 removal }\end{gathered}$

Return of blood to vascular system

\section{VV ECMO}

- Flow to right atrium

- Blood entrance into venous system

\section{VA ECMO}

- Flow to aorta

- Blood entrance into atrial system 
Table 1: Pharmacokinetic Changes in Critically III Patients ${ }^{4}$

\begin{tabular}{|c|c|c|}
\hline $\begin{array}{c}\text { Pharmacokinetic } \\
\text { Parameter }\end{array}$ & $\begin{array}{l}\text { Observed Physiologic Changes in } \\
\text { Critically III Patients }\end{array}$ & Resultant Pharmacokinetic Changes \\
\hline Absorption & $\begin{array}{l}\text { - Decreased gastrointestinal } \\
\text { and subcutaneous } \\
\text { perfusion }\end{array}$ & $\begin{array}{l}\text { - Decreased time to peak } \\
\text { concentration and area under the } \\
\text { curve }\end{array}$ \\
\hline Distribution & $\begin{array}{l}\text { - Decreased albumin } \\
\text { - Decrease tissue and organ } \\
\text { perfusion }\end{array}$ & $\begin{array}{l}\text { - Increased free drug concentration } \\
\text { and volumes of distribution for } \\
\text { albumin-bound medications } \\
\text { - Increased volumes of distribution } \\
\text { for hydrophilic medications } \\
\text { - Reduced free drug concentrations } \\
\text { in peripheral tissues }\end{array}$ \\
\hline Metabolism & $\begin{array}{l}\text { - Acute reduction in hepatic } \\
\text { blood flow } \\
\text { - Alteration of hepatic } \\
\text { enzyme function }\end{array}$ & $\begin{array}{l}\text { - Reduced clearance of hepatically- } \\
\text { cleared medications }\end{array}$ \\
\hline Elimination & $\begin{array}{l}\text { - Acute kidney insufficiency } \\
\text { - Alteration of active } \\
\text { transport of medications }\end{array}$ & $\begin{array}{l}\text { - Reduced clearance of renally- } \\
\text { cleared medications }\end{array}$ \\
\hline
\end{tabular}


Figure 2: Impact of ECMO on Drug Pharmacokinetics

\section{Change in PK Parameter \\ Relating Factor}

$\uparrow \mathrm{Vd}$

Priming of tubing

Hemodilution

Drug sequestration within tubing/circuit

SIRS/Sepsis

Organ failure

Hydrophilicity of drug

个 Cl SIRS/Sepsis

Drug inactivation within circuit

$\downarrow \mathrm{Cl} \quad$ Organ failure

$\uparrow \downarrow \mathrm{Cl} \quad$ Hydrophilicity of drug ${ }^{*}$

Lipophilicity of drug"

$\downarrow$ Cmax $\quad$ Priming of tubing

Hemodilution

Drug sequestration within tubing/circuit

Hydrophilicity of drug

- Dependent on renal function, \# dependent on hepatic function 